\title{
La elaboración de planes de salvaguardia con participación ciudadana para el patrimonio inmaterial agropecuario y pesquero
}

\author{
En febrero de 2016 el Instituto Andaluz del Patrimonio Histórico puso en marcha el I Seminario de \\ Patrimonio Inmaterial de Andalucía: el Atlas del patrimonio inmaterial, un viaje de ida y vuelta, que reunió \\ a representantes de actividades artesanales del sector agropecuario y pesquero de la región. Partiendo \\ de la experiencia previa del IAPH en el Atlas del Patrimonio Inmaterial, en el seminario se analizaron \\ los riegos y valores relacionados con determinados oficios y saberes tradicionales vinculados con el \\ aprovechamiento de recursos primarios, buscando elaborar las I Recomendaciones para la Salvaguarda \\ del Patrimonio Inmaterial relacionado con estas actividades que permitieran encontrar las mejores \\ fórmulas para garantizar su viabilidad.
}

Gema Carrera Díaz | Centro de Documentación y Estudios, IAPH

URL de la contribución <www.iaph.es/revistaph/index.php/revistaph/article/view/3835>

\author{
"Que este patrimonio no haya que conservarlo, \\ sino simplemente que podamos vivirlo" \\ Rafael Villardén, cabrero
}

El I Seminario de Patrimonio Inmaterial de Andalucía ${ }^{1}$ reunió a representantes de actividades artesanales del sector agropecuario y pesquero como, por ejemplo, la agricultura de la pasa moscatel en la Axarquía, los corrales de pesca de la costa noroeste gaditana, la pesca fluvial de los riacheros del Guadalquivir, el pastoreo y la producción de queso en los montes de Granada, la vinicultura en la campiña de Jerez, el marisqueo en Doñana, el arte de almadraba, las salazones, o las salinas de interior de Andalucía.

En torno a estas actividades económicas y oficios culturalmente significativos se produce una doble dinámica aparentemente contradictoria: por un lado, la desaparición y desterritorialización por las políticas económicas y las tendencias globalizadoras del mercado y, por otro lado, la recuperación o territorialización gracias a otras formas de activación patrimonial en la que toman el protagonismo determinados colectivos sociales respaldados en mayor o menor medida por algunas instituciones.

La paradójica idea de salvaguarda que aporta la Convención de UNESCO, 2003, ligada a la transformación, al dinamismo y al cambio, resulta fundamen- talmente útil en estos casos. La continuidad de estas actividades no radica en una protección fosilizadora o en su conversión en un mero atractivo turístico, sino en favorecer esa capacidad continua de adaptación a los cambios sociales, políticos y económicos que afectan a sus protagonistas y a las estrategias que estos generan. De forma consuetudinaria y basadas en la experiencia, estas estrategias son también innovadoras y creativas. La falta generalizada de una visión holística y antropológica de la cultura y la sectorización de competencias produce contradicciones en la gestión que inciden muy negativamente sobre los grupos sociales y sus conocimientos tradicionales y por tanto, en el entorno, en sus actividades económicas y consecuentemente en su cultura.

En muchas ocasiones, las administraciones competentes en materias relacionadas con diferentes actividades productivas (agricultura, montes o actividades forestales, medio ambiente, artesanía, cultura...) han aplicado políticas, planificaciones y normas desde visiones reduccionistas de las diferentes esferas que les competen sin atender a las relaciones entres las mismas. Ello ha complicado y obstaculizado las acciones sociales de resistencia de sus protagonistas a las tendencias globalizadoras del mercado en nuestro territorio y ha favorecido, de forma consciente o inconsciente, la implantación de estas últimas y sus consecuen- 
tes costes culturales, sociales, económicos y ambientales, mermando notablemente su reproducción social (CARRERA DÍAZ, 2016).

A pesar de que desde diversas instancias se han realizado estudios, declaraciones, directivas, resoluciones que han promovido la dimensión socio-ecológica para la conservación de los espacios naturales, la biodiversidad y el desarrollo sostenible (Convenio sobre la Diversidad Biológica, PNUMA, Río de Janeiro, 1992; Programa Mab de UNESCO; Ley 42/2007 del Patrimonio Natural y de la Biodiversidad), la mayor parte de las políticas atienden a los socio-ecosistemas desde una perspectiva exclusivamente biofísica primando los aspectos naturales sobre los sociales y el conocimiento científico sobre el conocimiento tradicional.

Conscientes de esta problemática, y con el objeto de crear un espacio estable de diálogo, debate y colaboración entre agentes públicos, privados y sociedad civil para la gestión colaborativa del patrimonio inmaterial de Andalucía, el IAPH inaugura los seminarios de patrimonio inmaterial, centrándose en esta ocasión en actividades tradicionales representativas de diferentes sectores productivos y distintos territorios andaluces y agrupadas en dos sesiones temáticas: agroalimentación y pesca.

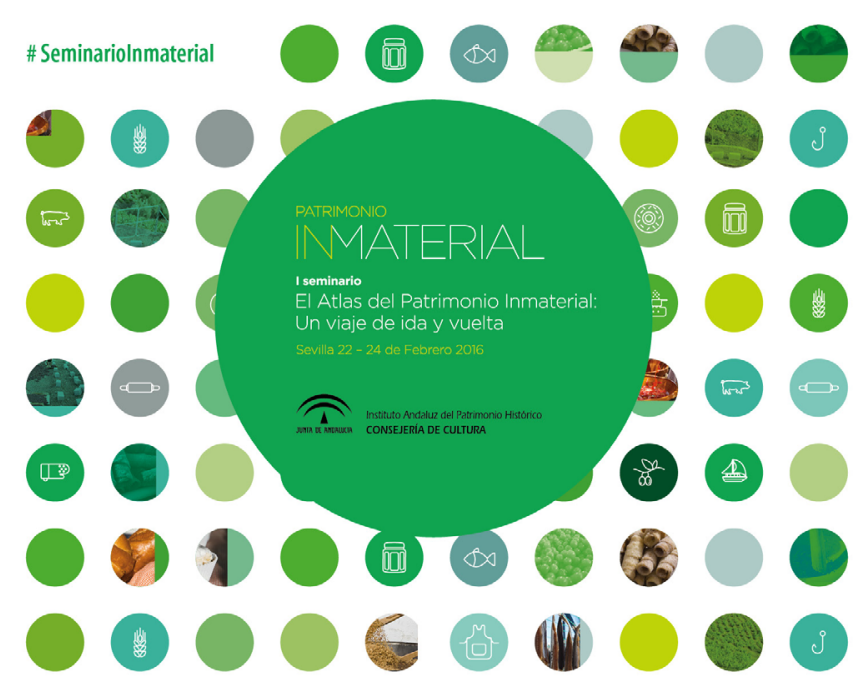

Cartel del seminario
Partiendo de la experiencia previa en el Atlas del Patrimonio Inmaterial, en el seminario se pretendía analizar los riegos y valores relacionados con determinados oficios y saberes tradicionales vinculados con el aprovechamiento de recursos primarios (agropecuarios o pesqueros) o con su transformación básica. Durante el proceso documental del Atlas del patrimonio Inmaterial de Andalucía, se constaró que dependiendo de diferentes dinámicas, estos oficios tienen mayores o menores posibilidades de continuidad. Parte de estas posibilidades están relacionadas con los colectivos o actores que en torno a las mismas activan procesos de identificación local y estrategias familiares y grupales de reproducción social y simbólica tan importantes para su continuidad, muchas veces minusvaloradas. Parte de sus limitaciones están relacionadas con las instrumentalizaciones o reglamentaciones políticas y económicas que se realizan en torno a ellos o en los territorios en los que se encuentran (normativas de medio ambiente, sanidad, alimentación, políticas agrarias o pesqueras, etcétera).

"Hay que aprender qué hay que mantener, qué abandonar, y qué tomar-adaptar para la tradición....Yo vi que estaba a punto de extinguirme y decidí sobrevivir;....hacer lo que han hecho toda su vida ahora es un delito" Cabrero

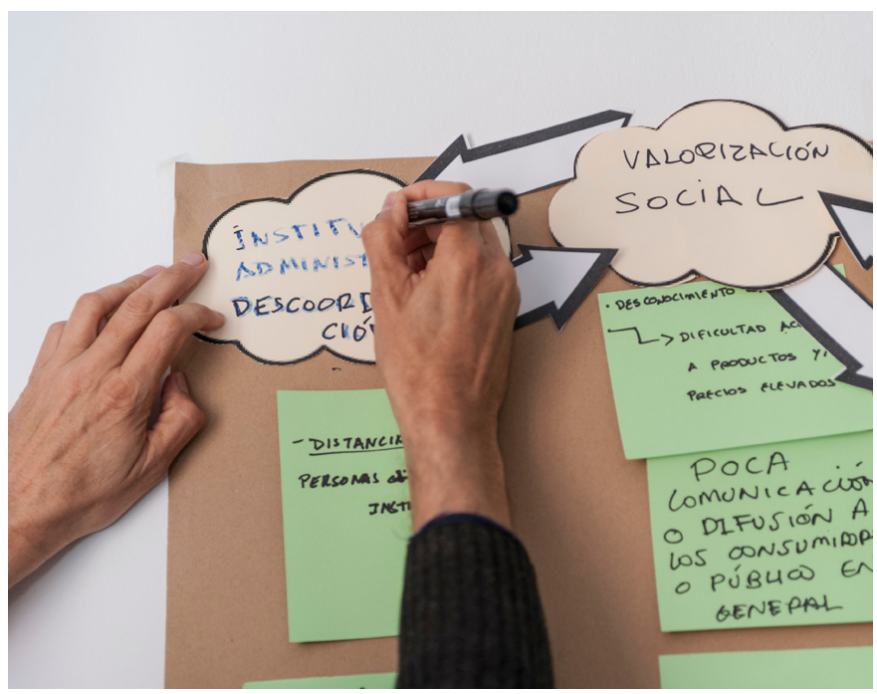

Taller participativo | foto Fondo Gráfico IAPH (Lidia Castro) 
"Adaptarse sin perder esencia es muy importante para cualquier industria"

Bodeguera

Acordar entre todos los agentes posibles, los límites y presiones que los propios protagonistas identifican y con las que se enfrentan día a día, se convierte en una tarea prioritaria para esta nueva etapa del Atlas del patrimonio Inmaterial de Andalucía, en su primer viaje de vuelta.

Ello explica el objetivo último de este I seminario: elaborar las I Recomendaciones para la Salvaguarda del Patrimonio Inmaterial relacionado con la producción agroalimentaria y pesquera que nos permitan encontrar las mejores fórmulas para garantizar la viabilidad de estas actividades. Y ello no por un sentimiento nostálgico conservacionista de la tradición, sino por constituir un modelo de desarrollo social y territorial basado, tal y como se identificó en el seminario, en valores identitarios, ambientales, culturales, sociales, nutricionales, ecológicos que resultan ejemplares de cómo los seres humanos pueden incidir positivamente en los socioecosistemas de los que forman parte, proveyendo de mecanismos que contribuyen al mantenimiento de sus funciones ecológicas fundamentales, propiciando la diversidad biológica y cultural y favoreciendo la resiliencia de estos socioecosistemas (ESCALERA REYES, 2013).

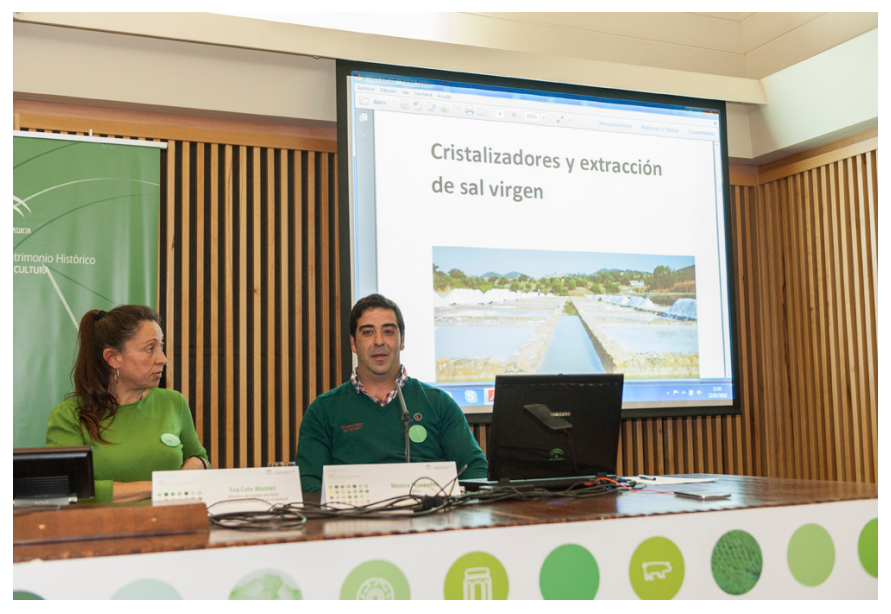

Mesa de presentación
Para poder elaborar un avance de dichas recomendaciones se planteó la siguiente estructura de seminario para hacer de él un encuentro participativo con resultados generados de manera colectiva²:

1. Relatos e historias de vida por parte de personas relacionadas con la producción agroalimentaria y pesquera con carácter artesanal. Se pretendía así romper con las dinámicas generalizadas de situar al conocimiento experto y técnico por encima del conocimiento tradicional.

2. Presentación de proyectos y actuaciones seleccionadas relacionadas con las temáticas del seminario ${ }^{3}$.

3. Expositores de productos alimenticios y degustación de productos de sociedades gastronómicas de Andalucía ${ }^{4}$.

\section{Relatoría Creativa.}

5. Taller participativo.

\section{Presencia en las redes sociales ${ }^{5}$.}

Participó en el proceso un grupo muy activo y diverso compuesto por personas relacionadas con estas actividades productivas, agentes públicos y privados relacionados con la gestión del patrimonio cultural, medioambiental, agrícola, pesquero, artesanal, turístico, investigadores, etc. Además de sus propias experien-

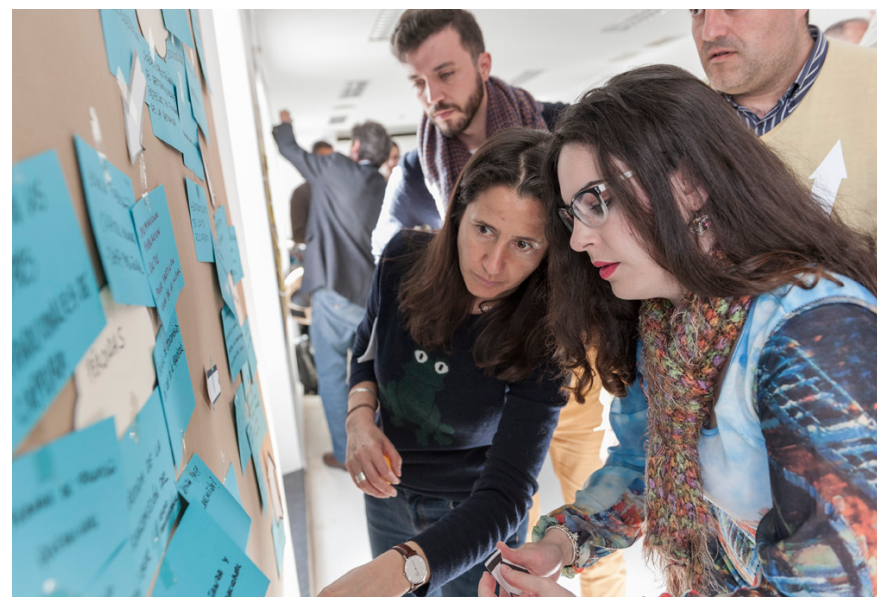

Taller participativo 
cias, este grupo enriqueció sus conocimientos previos con la convivencia mantenida a lo largo del seminario y mediante el intercambio de información que se ha ido produciendo durante su desarrollo, muy especialmente durante la exposición de los relatos de vidas de los protagonistas y de los proyectos presentados.

A los protagonistas de los relatos de vida se les ofeció una estructra básica para articularlos y cumplir con los objetivos analíticos y propositivos del seminario: ¿cuál es su actividad? ¿dónde la realiza? ¿desde cuándo? ¿de quién y cómo la aprendió? ¿cuáles son sus valores o por qué es importante? ¿qué problemas tiene? ¿qué estrategias sigue para continuar su actividad? ¿qué ayudas recibe? ¿cuáles crees que serían necesarias?

Tras dos días de intercambio de conocimientos y proyectos o actuaciones en torno a los valores y problemáticas de estas actividades productivas, una doble relatoría sintetizó de forma verbal y pictórica los riegos, valores y estrategias identificados por nuestros ponentes.

Durante todo el proceso, se identificaron algunos valores comunes como el afecto que por los saberes y oficios tradicionales expresan sus detentadores así como la apropiación simbólica del medio en el que lo desempeñan (mar, tierra...) y la aportación de estos saberes a calidad de la alimentación andaluza, a la diversidad cultural y a la biodiversidad.

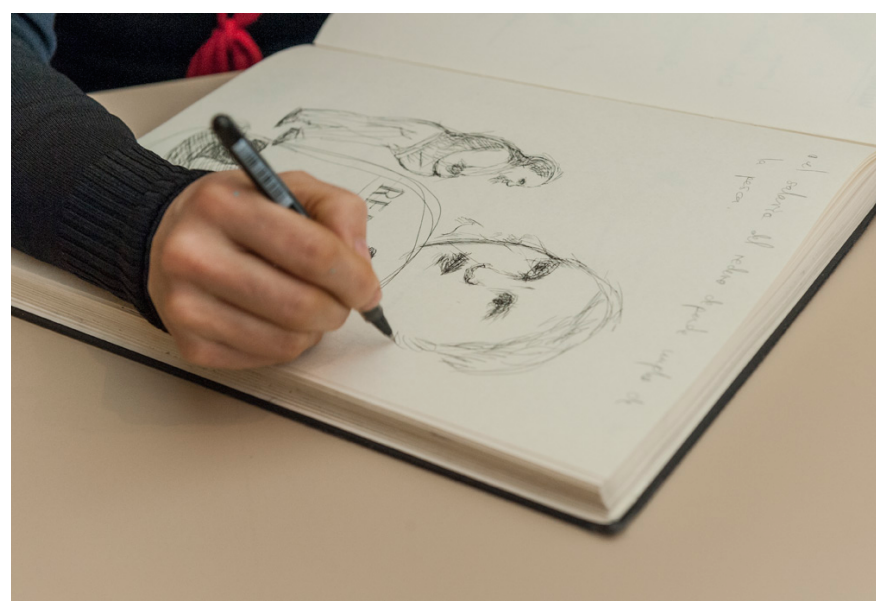

Bocetos para el mural de la relatoría
"La mejor pasa del mundo... es cuidada como un merengue..." Pasera

"el polen es el principio de la vida. Las abejas son parte del territorio, y cada cucharada de miel, miles de viajes de cada abeja... porque en un kilo de miel hay un millón de flores" Apicultora

"conocerme las 1500 botas, porque cada una tiene su personalidad y de allí nunca se mueven"

Enóloga

"Lo primero que hay que hacer es no dormir, y ser muy pesao, y amar tu negocio. Me he saltao a la torera todo lo que he podido, porque mi producto quiero que sea virgen (algo que me dijo mi padre: no hay ninguna sal virgen, y es una persona sabia)"

Salinero

Particularmente se resaltó el valor de la tierra y su importancia para la memoria colectiva. Se recalcó la adaptación ecológica, así como la vinculación e identificación del ser humano al medio (horario solar, materiales endógenos, 365 días de labor, estaciones, peligros de la contaminación, sobreexplotación y mercados invasores...).

"del duro trabajo de la pasa he podido estudiar (...) si yo pudiera vivir de esto aquí me quedaría. (... ) En Andalucía somos tierra, somos mar, somos ganadería"

Pasera

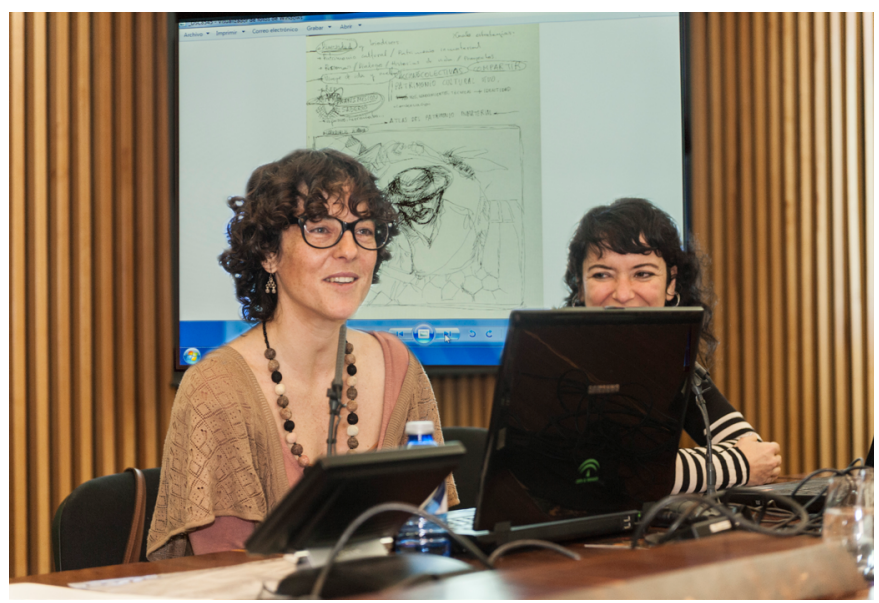

Relatoría del seminario | fotos Fondo Gráfico IAPH (Lidia Castro) 
Tabla 1. Síntesis de las medidas de salvaguarda propuestas en el taller paritcipativo

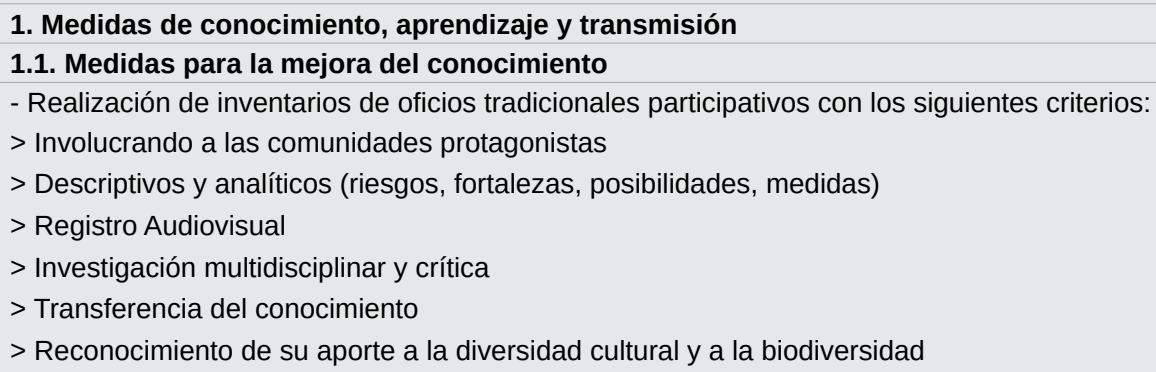

\subsection{Educación formal}

> Elaboración de planes educativos que integren estos conocimientos y desarrollo curricular en las escuelas de:

- Ecología Alimentaria

- Conocimientos y oficios tradicionales relacionados con la producción agropecuaria y pesquera

$>$ Elaboración de contenidos y unidades didácticas dirigidas a la educación primaria y educación secundaria obligatoria

$>$ Campañas informativas en las escuelas

$>$ Recuperación de Escuelas Taller y de oficios

\subsection{Educación no formal}

$>$ Fomento la trasmisión de saberes de forma intergeneracional (Comunidad educativa territorializada)

$>$ Encuentros entre agricultores y productores. Formación en el uso de variedades locales de verduras y hortalizas

\subsection{Transferencia y difusión}

$>$ Exposiciones fotográficas (fotografías antiguas, implicación de los ayuntamientos) Concursos de fotografías y documentales

> Campañas de comunicación creadas por los protagonistas: testimonios en primera persona en medios de comunicación

> Coloquios de participación y comunicación entre la administración, sector afectado y ciudadanía

2. Medidas legislativas, normativas. "Las leyes injustas no hay que cumplirlas, hay que cambiarlas"

2.1. Análisis de la situación normativa actual y su impacto en el patrimonio cultural inmaterial

> Estudio, recopilación y análisis de la normativa de aplicación

$>$ Análisis de las normativas que afectan a la producción artesanal

> Vigilancia del impacto de las normativas (europeas, estatales, autonómicas) en la destrucción del patrimonio inmaterial relacionados con la agricultura, la ganadería, la pesca...

Se enfatizó la importancia de la transmisión oral del conocimiento y la necesidad de reconocimiento profesional, de nuevas formas de aprendizaje y de organización colectiva. Se identificó como una gran amenaza la escasa valoración otorgada a estos conocimientos por parte de los centros de decisión, poder y demanda, así como la necesidad de difundir sus valores.

Otro de los principales problemas identificados fueron los normativos y burocráticos relacionados también con la falta de formación de técnicos y la acción de tabula rasa que ejercen las legislaciones (eliminado conocimientos tradicionales de gran valor cultural y ambiental al prohibir actividades productivas de mayor y menor impacto en una misma norma); o debido a la aplicación de las normativas europeas sin tener en cuenta excepcionalidades (producción artesanal de quesos, pesca artesanal...) y sin abrir la ventana a la flexibilidad que todas ellas contemplan. Relacionado con ello, se identificó como un problema estructural, la distribución desigualitaria de la tierra en Andalucía "la tierra, que está muy mal repartida" y el desequilibrio profundo e insalvable provocado por las políticas agrarias a partir de esta desigualdad.

Continuamente fue reivindicado el papel de la mujer en la transmisión de oficios y saberes al tiempo que su escasa visibilidad y reconocimiento. 


\subsection{Flexibilidad, coordinación y simplificación de normativas}

> Flexibilización y desburocratización

$>$ reciclaje funcionarial y administrativo

$>$ Reforma agraria y pesquera participada

> Programas de integración de las políticas que actúan sobre el patrimonio desde el ámbito cultural con otras políticas sectoriales

2.3. Gobernanza y participación social en la generación de normativas

$>$ Adaptación de las normas a las realidades territorialesy sociales concretas

> Plan de gestión integrador entre sectores y administración

> gobernanza: nuevas formas de organización de la administración pública

3. Medidas de fomento

3.1. Relacionadas con la artesanía y comercio

$>$ Premios a productores y empresas mediante

$>$ Fomento de canales cortos de comercialización: mercados locales artesanales

$>$ Fomento del consumo de productos locales y de calidad

$>$ Uso de TIC para la difusión y venta directa

$>$ Creación de una línea específica de ayudas económicas, asesoramiento técnico

$>$ Exenciones fiscales a los productores tradicionales

$>$ Fomento de las denominaciones de origen / calidad..

> Dignificación de los profesionales artesanales tradicionales (sueldos, condiciones laborales...)

$>$ Educación y colaboración ciudadana

$>$ Uso de bienes comunes: cultivo de variedades locales de verduras y hortalizas en terrenos municipales

3.2. Relacionadas con el turismo

$>$ Turismo responsable experiencial relacionado con la práctica de oficios tradicionales

$>$ Visitas guiadas de escolares a productores artesanales de alimentos

\subsection{Relacionadas con educación y sanidad}

> Fomentar prácticas y hábitos de consumo saludables y responsables con el entorno y los productos locales

$>$ Servicios de catering con productos de proximidad y uso de recetas tradicionales (informando sobre valores culturales y nutricionales de los productos y recetas)en instituciones públicas (fundamentalmente en centros educativos y sanitarios)

"Las mujeres... son la necesidad hecha virtud y lo lograron rompiendo la oligarquía, la jerarquía de espacios y el sistema machista que no le permitía tener ni personalidad jurídica a una mujer -Viuda de-"

Bodeguera. Maestro Sierra

Por otro lado, se reivindicó el derecho a la soberanía alimentaria y se expresó el deseo de que "este patrimonio no haya que conservarlo, sino simplemente que podamos vivirlo".

Con estos precedentes, el último día del encuentro, los presentes dedicaron sus esfuerzos a la celebración de un taller participativo en el que se empleó el método
VIPP (Visualización de Procesos Participativos) para poder alcanzar una mayor contribución de los participantes en la identificación de riesgos, valores y estrategias para la toma de decisiones, planificación o procesos de cambio en torno al patrimonio inmaterial relacionado con el sector agroalimentario y pesquero.

Esta forma de construir colectivamente el conocimiento permitió diseñar de manera participada una serie de medidas concretas para la salvaguarda de estos oficios tradicionales en torno a la siguiente estructura: 1) medidas de conocimiento, aprendizaje y transmisión; 2) medidas normativas y legislativas; 3) medidas de fomento sintetizadas en la tabla 1. 

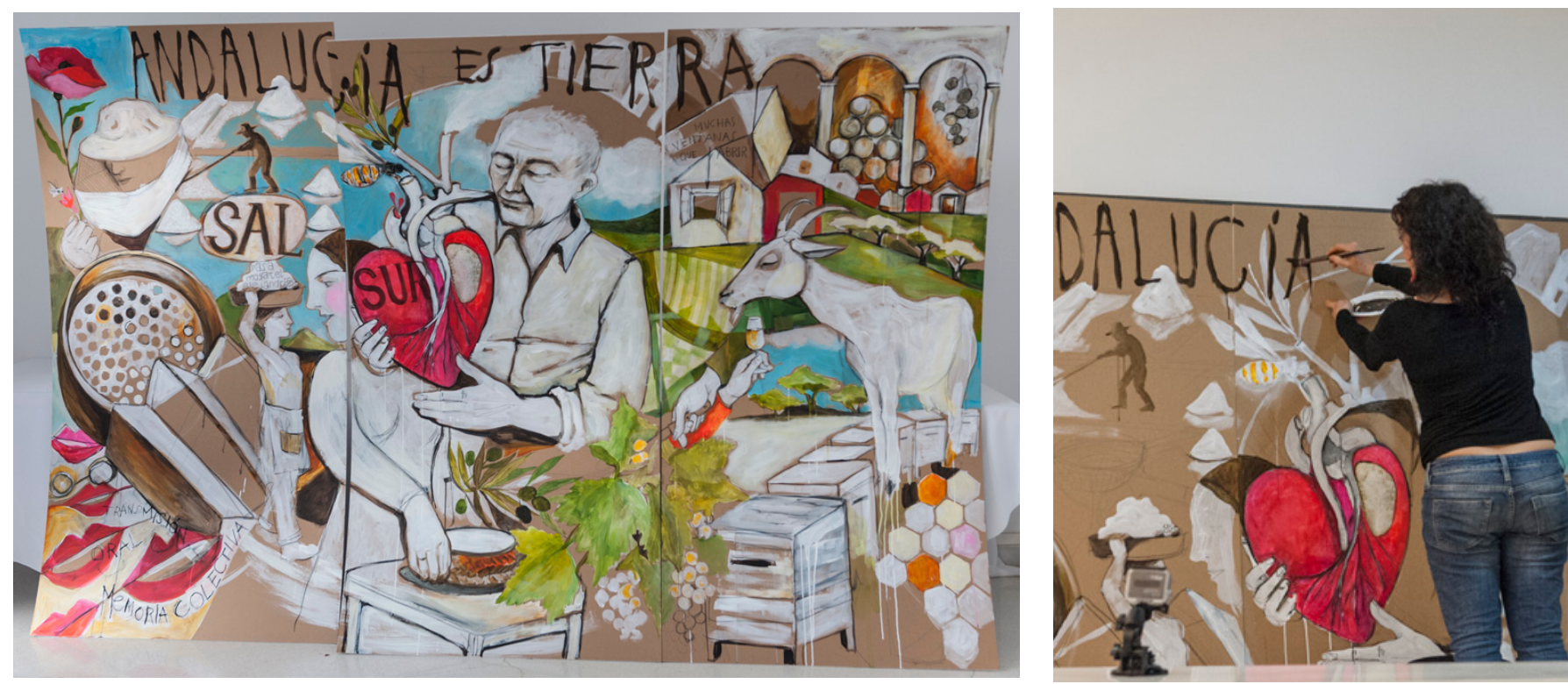

Mural realizado por la relatoría. Maria del Mar Camacho. La Mari | foto Fondo Gráfico IAPH (Isabel Dugo)

\section{En definitiva y como conclusión retomo las palabras de la relatoría del seminario:}

"Todas las personas hemos hecho en estos dos días pasados un viaje de ida y vuelta: por aire, tierra y mar; entre el pasado y el presente; entre conocimientos (saberes tradicionales y científico-técnico..) y oficios, traspasando fronteras a veces imposibles (o departamentos, de lo público y lo privado, demarcaciones territoriales ajenas...). Y lo hemos hecho de una manera fluida, en la que se enlazan por sí mismas, con una dialéctica propia: oficios, saberes, fiestas (perpetuación de modelos), artesanías, hablas y modos de expresión, alimentación y cocinas, indumentarias, aparejos y aperos, ecología y cuidados, integración social... Reconociéndonos (volviendo a conocernos) como comunidad diversa. Porque ha sido un lugar de encuentro, de descubrimiento, de conocimiento, participación, reconocimiento, y colaboración. Lo que nos interesa de este patrimonio inmaterial es su capacidad de cambiar (como acción creativa colectiva), por ser cultura viva, participada por los individuos y grupos sociales en el territorio que habitan, cuidándolo y preservándolo en una relación sostenible: y porque consiste en una actitud y aptitud de ejercicio del derecho al territorio que mantienen los pueblos. Desde la resistencia, la lucha y sobre todo, el cuidado de la tierra y el mar" Marián Ruiz Jiménez, relatora. AAIICC
Este encuentro fue clausurado "de repente" con versos improvisados de dos troveros, poetas y campesinos alpujarreños de la Contraviesa.

\section{Agradecimiento}

Además del interés e impulso de la dirección del IAPH para la organización de este seminario, ha sido fundamental el trabajo realizado por las personas que han participado en su organización y desarrollo demostrando, una vez más, la profesionalidad y capacidad de compromiso y trabajo en equipo: Inmaculada Álvarez, Aniceto Delgado, Isabel Durán, Silvia Fernández, Martín Fernández, Carmen Jorge, Susana Limón, Isabel Luque, Fátima Marín, Myriam Olmedo, Carlos Romero, Francisco Salado, Carmen Sánchez, José Manuel Santos. La Agencia Pública empresarial ÁGAPA ha colaborado haciéndose cargo del registro y edición de videos durante el desarrollo de las jornadas. La empresa LB plan ha realizado de manera excepcional la labor de secretaría técnica. 


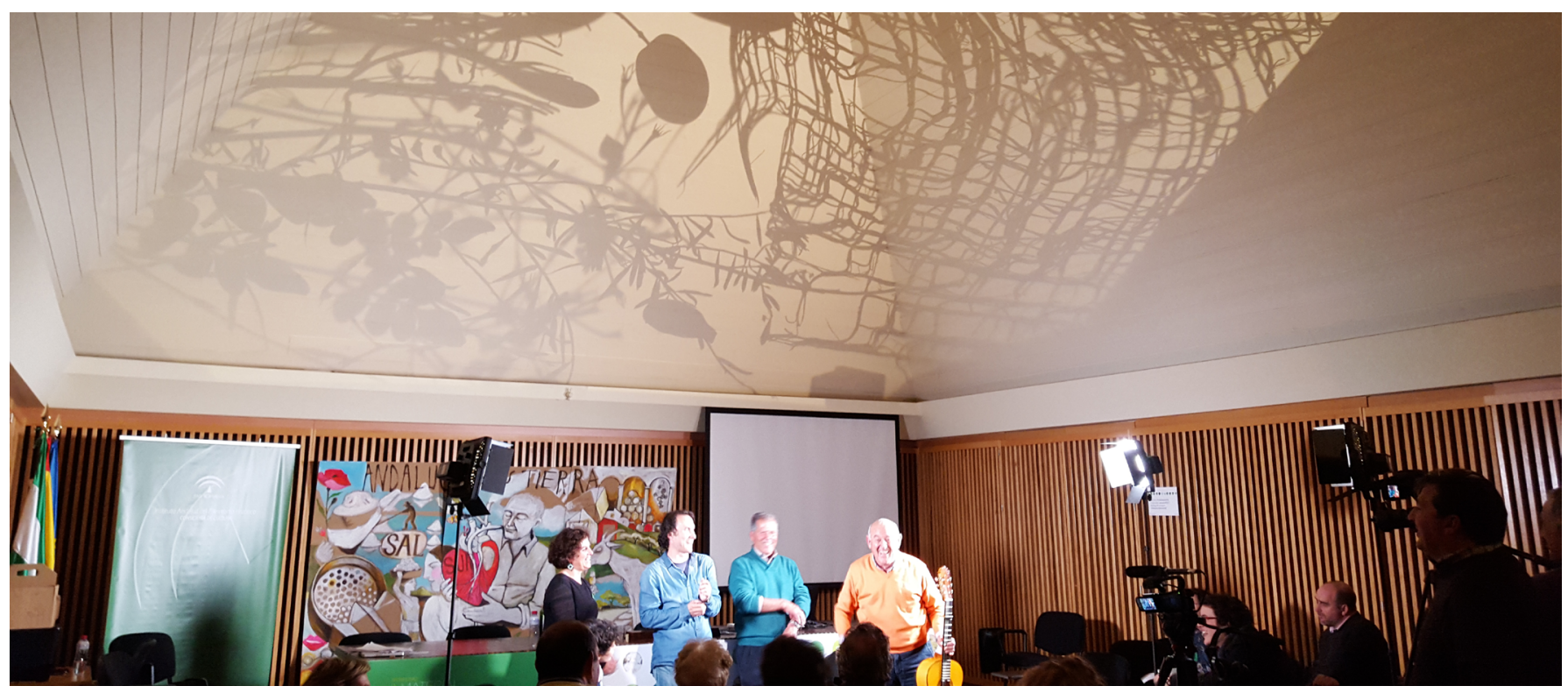

Troveros de Alpujarra y Contraviesa | foto Fondo Gráfico IAPH (Lidia Castro)

\section{NOTAS}

1. Web del Seminario Un viaje de ida y vuelta: Re-conócete <http://www.iaph.es/web/canales/formacion/cursos/seminario_patrimonio_inmaterial/index.html> y post en el blog de la Consejería de Cultura de la Junta de Andalucía <http://www1.ccul.junta-andalucia.es/cultura/ blog/patrimonio-inmaterial-y-participacion-social-el-atlas-del-patrimonio-inmaterial-de-andalucia-y-los-seminarios-de-patrimonio-inmaterial-como-espacio-abierto-de-dialogo/> [Consulta: 19/09/2016]

2. Programa del Seminario <http://www.iaph.es/export/sites/default/galerias/patrimonio-cultural/documentos/programa_seminario_patrimonio_inmaterial.pdf> [Consulta: 19/09/2016]

3. Exposición de proyectos y experiencias <http://www. iaph.es/export/sites/default/galerias/patrimonio-cultural/ documentos/Proyectos_seminario.pdf> [Consulta: 19/09 /2016]

4. Patrocinadores sesión gastronómica <http://www. iaph.es/export/sites/default/galerias/patrimonio-cultural/ documentos/PATROCINADORES.pdf> [Consulta: 19/09/ 2016]
5. El Seminario en Facebook, Twitter e Instagram <http:// www.iaph.es/web/canales/formacion/cursos/seminario_ patrimonio_inmaterial/presentacion/redes.html $>$ [Consulta: $19 / 09 / 2016]$

\section{BIBLIOGRAFÍA}

- CARRERA DíAZ, G. (2016) Propuesta metodológica para la documentación y gestión del patrimonio cultural inmaterial como estrategia de desarrollo social y territorial. El patrimonio como recurso para vivir. Tesis doctoral. Universidad de Sevilla, 2016

- ESCALERA REYES, J. (2013) Amor a la tierra: identidades colectivas y resiliencia de los socioecosistemas. En AA.VV Complejidad y Ciencias sociales. Universidad internacional de Andalucía, 2013 